\title{
Do Humor Styles Mediate or Moderate the Relationship Between Self-Criticism and Neediness and Depressive Symptoms?
}

\author{
Avi Besser, PhD, * Patrick Luyten, PhD, $¥ \S$ and Sidney J. Blatt, PhD//
}

\begin{abstract}
This study examined whether, in a community sample of Israeli adults $(N=335)$, benign (i.e., affiliative and self-enhancing) and injurious (i.e., aggressive and self-defeating) humor styles mediated or moderated the relationship between self-criticism and neediness, two traits that confer vulnerability to depression, on the one hand, and levels of depressive symptoms, on the other. There was no evidence of any moderating effect of humor styles on the relationship between self-criticism and neediness and depressive symptoms. However, results indicated that the use of injurious styles of humor mediated the relationship between self-criticism and depressive symptoms as well as the relationship between neediness and depressive symptoms. Moreover, the relationship between neediness and depressive symptoms was also mediated by low levels of benign humor. These findings may have important implications for theories concerning vulnerability to depressive symptoms and intervention strategies.
\end{abstract}

Key Words: Self-criticism, neediness, humor, depression, affect regulation

(J Nerv Ment Dis 2011;199: 757-764)

G rowing evidence indicates that high levels of self-criticism and neediness (i.e., maladaptive dependency) are associated with increased vulnerability to depression (see Blatt and Luyten, 2010; Mongrain and Leather, 2006; Schulte et al., 2008; Zuroff et al., 2004). However, the mechanisms by which these personality dimensions confer vulnerability to depression are still relatively poorly understood. Increasing evidence suggests that both self-criticism and neediness are associated with maladaptive affect-regulation strategies, particularly in the context of close interpersonal relationships, which may partially explain their association with depression [see Blatt and Luyten, 2009, for a review]. Humor, particularly the use of benign versus injurious styles of humor, may play an important but, until now, relatively neglected role in this context. Indeed, studies increasingly point to the importance of humor as an affect-regulation strategy, particularly in interpersonal relationships (e.g., Besser A, Luyten P, Mayes LC Adult attachment and distress: The mediating role of humor styles [submitted for publication, 2011]; Besser and Zeigler-Hill, 2011; Martin, 2007; Miczo et al., 2009; Taber et al., 2007; Zeigler-Hill and Besser, 2011). Congruent with these findings, it has been suggested that humor may play an important role in resiliency in the face of adversity (Fonagy et al., 1994; Luyten et al., 2011; Martin, 2001, 2007; Vaillant, 1977, 2000). In light of this previous work, the present study explored the roles of adaptive and maladaptive humor styles as mediators or

*Department of Behavioral Sciences and Center for Research in Personality, Life Transitions, and Stressful Life Events, Sapir Academic College, Ashkelon, Israel $\dagger$ Department of Psychology, University of Leuven, Leuven, Belgium; $₫$ Research Department of Clinical, Educational, and Health Psychology, University College London, London, UK; §Yale Child Study Center New Haven, CT; and ||Departments of Psychiatry and Psychology, Yale University, New Haven, CT.

Send reprint requests to Avi Besser, PhD, Department of Behavioral Sciences

and Center for Research in Personality, Life Transitions, and Stressful Life

Events, Sapir Academic College, D. N. Hof Ashkelon 79165, Israel.

E-mail: besser@mail.sapir.ac.il.

Copyright (C) 2011 by Lippincott Williams \& Wilkins

ISSN: 0022-3018/11/19910-0757

DOI: $10.1097 /$ NMD.0b013e31822fc9a8 moderators of the associations of depressive symptoms with the vulnerability factors of self-criticism and neediness.

\section{Self-Criticism, Neediness, and Depression}

Personality development, according to Blatt (1974, 1991, 2004, 2008), involves the integration of a person's development of selfdefinition with the capacity for interpersonal relatedness. Self-definition refers to "the development of a realistic, essentially positive and increasingly integrated self-definition and self-identity" (Blatt, 1991, p. 453). Interpersonal relatedness refers to "the development of the capacity to establish increasingly mature, reciprocal, and satisfying interpersonal relationships" (Blatt, 1991, p. 453). Differences in the relative emphasis on processes of relatedness and self-definition delineate two fundamental personality styles, each with distinct modes of cognition, modes of defense, meaning-making processes, and coping strategies (Besser and Priel, 2003; Besser and Priel, 2011; Besser et al., 2008b; Blatt, 2008). However, an exaggerated, one-sided emphasis on one of these two normal developmental lines may lead to extreme personality traits that confer vulnerability to depression and various other forms of psychopathology. More specifically, intense self-criticism reflects a distortion in the development of self-definition, whereas intense dependency reflects impairment in the development of interpersonal relatedness (Blatt, 2008).

More than three decades of research suggest that self-criticisman exaggerated, distorted emphasis on self-definition associated with harsh personal standards, heightened strivings for mastery and achievement, and a marked need for acknowledgment - does indeed confer vulnerability to depression (Beck, 1983; Blatt, 1974, 2004, 2008; Blatt and Luyten, 2009; Blatt et al., 1982). Both cross-sectional and longitudinal studies have shown that highly self-critical individuals are more susceptible to depression (see reviews in Besser and Priel, 2005; Besser et al., 2008a; Blatt, 2004; Zuroff et al., 2004).

In contrast, findings for dependency have been somewhat more mixed, with dependency showing elements of both vulnerability and resilience. For example, high levels of dependency have been associated not only with depression (see reviews in Besser and Priel, 2005; Besser et al., 2008a; Blatt, 2004, 2008; Zuroff et al., 2004) but also with the perception of social support, which may mitigate feelings of depression (e.g., Besser and Priel, 2010; Blatt et al., 1995; Mongrain, 1998; Mongrain et al., 2004; Priel and Besser, 1999, 2000).

Subsequent research has isolated a more maladaptive, immature "neediness" or "dependence" factor from a more mature and adaptive "connectedness" or "relatedness" factor in existing measures of dependency, such as the Depressive Experiences Questionnaire and the Sociotropy-Autonomy Scale (Blatt et al., 1995, 1996; Rude and Burnham, 1995; Whiffen et al., 2000). Although the more adaptive factor ("connectedness" or "relatedness") reflects mature and reciprocal interpersonal concern with a relationship with a particular significant other (Besser and Priel, 2008; Campos et al., 2010, 2011), the maladaptive/vulnerability factor ("neediness" or "dependence") involves excessive preoccupation with the availability of love, nurturance, and support, together with strong fears of abandonment and rejection. Because this study focused on vulnerability to depression, we focused on the personality vulnerability factors to depression (i.e., self-criticism 
and neediness) and examined their relationships with humor styles and depressive symptoms.

\section{Self-Criticism, Neediness, and Humor}

Although, as noted, there is evidence to suggest that both selfcriticism and neediness are associated with increased vulnerability to depression, relatively little is known about the mechanisms involved in these associations. Previous research has mainly focused on affectregulation strategies associated with these personality dimensions, specifically in the context of interpersonal relationships, such as coping (Besser, 2004) and defense mechanisms (see also Besser and Priel, 2003, and Campos et al., 2011). Research in this area has suggested that both self-criticism and neediness are associated with so-called dysfunctional transactional cycles (Luyten et al., 2005, 2011; Wachtel, 1997). In these cycles, individuals with high levels of self-criticism and neediness generate, in part and largely unwillingly, their own stressful (interpersonal) environment. Because they are so critical and often have excessive personal standards, self-critical individuals tend to be competitive and ambivalent about relationships, which typically leads to dissatisfaction and conflicts in interpersonal relationships. Because of their strong fears of rejection and abandonment, individuals with high levels of neediness are often demanding and clingy in relationships, which increases the probability of rejection and abandonment. These cycles lead to further distress, which these individuals then typically attempt to regulate by becoming even more self-critical or needy, leading to vicious cycles characterized by even more self-criticism and fears of abandonment and rejection, respectively (Besser and Priel, 2005; Thompson and Zuroff, 1998, 1999).

Research to date has overlooked the potential role of humor in these vicious interpersonal cycles. Indeed, solid evidence indicates that humor, besides serving intrapersonal functions, also plays an important role in regulating distress within interpersonal relationships and thus might play an important role in the relationship between the personality dimensions of self-criticism and neediness and depression. For instance, Martin et al. (2003) developed a two-dimensional framework that includes a strong focus on both the intrapersonal and interpersonal nature and the consequences of humor. The framework suggests that two underlying dimensions reflect both the interpersonal nature of humor (i.e., injurious or benign) and the target of enhancement (i.e., the self or relationships with others).

The combination of these two dimensions yields four distinct humor styles, two that are adaptive (i.e., affiliative humor and selfenhancing humor) and two that are maladaptive (i.e., aggressive humor and self-defeating humor). Briefly, Martin et al. (2003) found that affiliative humor (i.e., benign humor that is used to enhance relationships with others, such as friendly banter) and self-enhancing humor (i.e., benign humor that is used to enhance the self, for example, to maintain a positive outlook during times of adversity) have positive effects on both feelings of well-being and interpersonal relationships (Butzer and Kuiper, 2008; Cann et al., 2008).

In contrast, aggressive humor (i.e., injurious humor that is used to enhance the self, such as ridiculing others) and self-defeating humor (i.e., injurious humor that is used to enhance relationships with others through actions such as belittling oneself) have typically been found to be associated with distress (see Martin, 2007, for a review), loneliness (Fitts et al., 2009), lower levels of relationship satisfaction (Cann et al., 2008), and being disliked by others (Kuiper and Leite, 2010). Moreover, a rapidly growing body of research has demonstrated that benign and injurious forms of humor are differentially associated with measures of psychological well-being, such as depression, anxiety, aggression, self-esteem, optimism, and social intimacy (Kazarian and Martin, 2004; Martin et al., 2003; Saroglou and Scariot, 2002). For example, both affiliative and self-enhancing styles of humor have been shown to be negatively related to depression, whereas the opposite pattern has been observed for self-defeating humor (Martin et al., 2003; see Martin, 2007, for a review).

To the best of our knowledge, no previous study has directly investigated whether humor styles moderate or mediate the relationship between self-criticism and neediness on the one hand and depression on the other. The only study to have addressed related issues was conducted by Frewen et al. (2008). These authors found an association between sociotropy, which is closely related to dependency, and self-defeating humor; however, they noted that a need for control, a subdimension of self-criticism, was related to aggressive humor (Frewen et al., 2008). Moreover, high levels of self-defeating humor and low levels of self-enhancing and affiliative humor were associated with high levels of depressive symptoms. However, Frewen et al. (2008) did not directly investigate the possible mediating or moderating role of humor styles in the relationship between these personality dimensions and depressive symptoms. In this study, we aimed to replicate and to extend their findings.

\section{The Present Study}

In light of recent research concerning the mediating role of humor in outcomes associated with personality vulnerability factors such as pathological narcissism (Besser and Zeigler-Hill, 2011; Zeigler-Hill and Besser, 2011) and insecure attachment styles (Besser A, Luyten P, Mayes LC Adult attachment and distress: The mediating role of humor styles [submitted for publication, 2011]), we were interested in examining whether humor styles mediate the associations between the personality vulnerability factors of self-criticism and neediness and depressive symptoms.

We expected that needy individuals primarily use injurious humor, specifically self-defeating humor styles, such as depicting the self as inferior, in attempts to receive care, love, and attention (e.g., "I let people laugh at me or make fun at my expense more than I should"). Moreover, although these individuals might be expected to avoid using aggressive humor for fear of losing others, they might use aggressive humor defensively to deny feelings of rejection and to assert the self (Martin, 2007; Vaillant, 1977). Likewise, although highly self-critical individuals were expected to primarily use injurious humor, specifically aggressive humor, to assert their autonomy and independence, they were also expected to use self-defeating strategies in their attempts to gain approval and recognition. Therefore, both self-criticism and neediness were expected to be positively related to the use of injurious humor styles and to be negatively related to the use of benign humor styles. Furthermore, in line with previous findings, injurious humor styles were expected to be positively related to depressive symptoms, whereas benign humor styles were expected to be negatively related to depressive symptoms.

We tested both mediation and moderation models for humor in the relationship between self-criticism and/or neediness on the one hand and depressive symptoms on the other. First, we tested whether humor styles mediate the relationship between these personality dimensions and depressive symptoms. Consistent with the extant literature on humor styles, we hypothesized that both low levels of benign humor styles and high levels of injurious humor styles would mediate the relationships between personality vulnerability factors and depressive symptoms. Second, we tested a competing but not necessarily mutually exclusive model (i.e., that humor styles moderate the relationship between the personality vulnerability factors of selfcriticism and neediness and depressive symptoms). Specifically, we hypothesized that high levels of benign and/or low levels of injurious humor would interact with self-criticism and neediness in the prediction of depressive symptoms, possibly moderating these relationships. That is, according to this model, individuals with high levels of self-criticism and/or neediness are expected to exhibit high levels of depressive symptoms only when they also report using low levels of benign and/or high levels of injurious humor. 


\section{METHODS}

\section{Participants}

Our sample consisted of 335 Jewish Israeli community participants (145 men and 190 women) who each reported being currently involved in a serious, committed romantic intimate relationship. Participants were unmarried young adults in their mid-20s (age range, 20 to 30 years; mean [SD], 24.54 [5.11]) who responded to a call for volunteers to take part in a study of personality and mood. Participants had, on average, more than 12 years of formal education (mean [SD], $12.71[1.05])$.

\section{Measures}

\section{The Depressive Experiences Questionnaire}

The Depressive Experiences Questionnaire (DEQ; Blatt et al., 1976) is a 66-item scale used to assess the two vulnerability factors in the present study: self-criticism and neediness. Self-criticism reflects concerns about failure and guilt, self-criticism, and being unable to meet high standards set by the self and by others (e.g., "It is not who you are, but what you have accomplished that counts"). The neediness subscale assesses excessive preoccupation with and fears about interpersonal relationships, devastating feelings of helplessness, fears and apprehension about separation and rejection, and intense concerns about the loss of gratification and support (e.g., "Without the support of others who are close to me, I would be helpless"). The selfcriticism and neediness factors were calculated using the scoring systems proposed by Blatt et al. (1976) and Rude and Burnham (1995), respectively. In accordance with the unit weight scoring system described by to Blatt et al. (1976), each of the standardized scores of the 66 items was multiplied by the factor weight coefficient obtained in the normed sample for the loadings on self-criticism. Scoring for the neediness scale was performed following the secondorder factor analyses proposed by Rude and Burnham (1995). In our sample, the estimates of internal consistency were $\alpha=0.88$ and $\alpha=0.91$ for self-criticism and neediness, respectively.

\section{Humor Styles Questionnaire}

The Humor Styles Questionnaire (HSQ; Martin et al., 2003) is a 32-item measure composed of four eight-item scales that assess different styles of humor: affiliative (e.g., "I laugh and joke a lot with my friends"), $\alpha=0.73$; self-enhancing (e.g., "My humorous outlook on life keeps me from getting overly upset or depressed about things"), $\alpha=0.78$; aggressive (e.g., "If someone makes a mistake, I will often tease them about it"), $\alpha=0.72$; and self-defeating (e.g., "I let people laugh at me or make fun at my expense more than I should"), $\alpha=0.81$. Respondents are asked to indicate the degree to which they agree or disagree with each item using a 7-point Likert-type scale. Martin et al. (2003) reported internal consistencies (Cronbach $\alpha$ ) of 0.80 for the affiliative scale, 0.81 for the selfenhancing scale, 0.77 for the aggressive scale, and 0.80 for the self-defeating scale.

\section{The Center for Epidemiological Studies Depression Scale}

The Center for Epidemiological Studies Depression Scale (CES-D; Radloff, 1977) is a 20-item scale designed to measure the severity of current depression in the general population. The items, each of which is assessed on a scale from 0 to 3, measure the following aspects of depression: depressed mood, feelings of guilt and worthlessness, feelings of helplessness and hopelessness, psychomotor retardation, loss of appetite, and sleep disturbances (Radloff, 1977). This scale has been shown to be valid and reliable in many different Israeli samples (e.g., see Besser and Priel, 2005). It is a well-known measure that has acceptable levels of internal consistency (see
Radloff, 1977). Extensive evidence from a variety of samples attests to the reliability and validity of the CES-D (Eaton et al., 2004). In the present sample, the estimate of internal consistency was $\alpha=0.90$.

\section{Procedure}

This study was approved by the ethical committee of the Department of Behavioral Sciences of Sapir Academic College, Israel. All respondents provided written informed consent and were provided the opportunity to discontinue the study at any time. None chose to do so. The participants responded to an advertisement for volunteers to take part in a study on personality and mood that was posted in various public areas (e.g., clubs, hotels, restaurants, shops). The individuals who responded were asked on whether they would be willing to complete a series of questionnaires about personality, mood, and humor. Only those who agreed to take part in the study were invited to participate, and all participants were met individually in their homes. Upon the researcher's arrival, each participant completed the questionnaire package individually. After completing a demographic questionnaire, each participant completed the DEQ, HSQ, and CES-D. All questionnaires were translated using the backtranslation procedure and administered in Hebrew. Potential order effects were controlled through randomized presentation of the questionnaires within and between participants. After they had completed the questionnaires, participants were given a written debriefing. Participation in the study was voluntary, and participants were not paid or compensated for their participation.

\section{Data Analysis}

We used the Kolmogorov-Smirnov test (Smirnov, 1948), the Lilliefors test (Lilliefors, 1967), and the Shapiro-Wilk test (Shapiro and Wilk, 1965) to examine the normality of the distributions of the variables in the present study. The results of these tests indicated that the distributions of these measures were relatively normal $(p>0.30)$. We also examined multicollinearity among self-criticism, neediness, humor styles, and depression. The eigenvalues of the scaled and uncentered cross-products matrix, condition indices, and variance decomposition proportions, along with variance inflation factors and tolerances from multicollinearity analyses, indicated the absence of multicollinearity. We used Structural Equation Modeling (SEM; Hoyle and Smith, 1994) to investigate the proposed mediation model in two stages. To test the overall fit of the measurement model, we used Confirmatory Factor Analysis (CFA; Anderson and Gerbing, 1988) to investigate the fit of a model with two latent factors (benign humor and injurious humor), each defined by two observed variables. Afterward, we fitted a model to examine the direct associations between individual personality vulnerability factors (i.e., self-criticism [Fig. 1] and neediness [Fig. 2]) and depressive symptoms, as well as their combined direct association with depressive symptoms (Fig. 3). Finally, we fitted the proposed mediating model of the association between self-criticism and neediness and depressive symptoms with two latent factors (i.e., benign and injurious humor) as mediators or moderators (controlling for their shared variance), following the criteria of Baron and Kenny (1986) for mediation and moderation.

Using this strategy for testing the mediational hypothesis, we first analyzed the direct associations between each of the personalityvulnerability factors and depressive symptoms. Afterward, we specified the models of the direct and indirect associations. The following fit indices were used: the chi-squared/df ratio, the Root Mean Square Error of Approximation (RMSEA), the Comparative Fit Index (CFI), and the Non-Normed Fit Index (NNFI). A model in which chisquared $/ d f$ ratio was 3 or less, in which CFI and NNFI were greater than 0.90 , and in which the RMSEA index was between 0.00 and 0.06 with confidence intervals between 0.00 and 0.08 ( $\mathrm{Hu}$ and Bentler, 1999) was considered acceptable (Kelloway, 1998). The zero-order correlations between the study variables are summarized in Table 1. 




FIGURE 1. A mediational model of the relationships among self-criticism, humor styles, and depressive symptoms. Rectangles indicate measured variables, and the large circles represent latent constructs. Small circles reflect residuals (e). Bold numbers above or near endogenous variables represent the amount of variance explained $\left(R^{2}\right)$. The bidirectional arrow depicts covariance and unidirectional arrows depict hypothesized directional links. Standardized maximum-likelihood parameters were used. The number in parentheses is the beta value before humor-construct scores (assumed mediators) were entered into the model $\left(\Delta R^{2}=11 \%\right)$. Bold estimates are statistically significant. CES-D indicates Center for Epidemiological Studies Depression Scale. ${ }^{*} p<0.05$, two-tailed. $* * p<0.01$, two-tailed. $* * * p<0.001$, two-tailed.

We evaluated the proposed mediation models by studying the sampling variability of estimates of the indirect association using the bootstrap framework proposed by Shrout and Bolger (2002) and Mallinckrodt et al. (2006). Using Analysis of Moment Structures (Version 18.0.0; Arbuckle, 2009), we implemented this procedure in the direct and mediational models, which involved drawing 5000 bootstrapping samples. We found that $100 \%$ of the bootstrap samples converged for all of the tested models. The two-sided $95 \%$ confidence intervals and the confidence intervals based on the bias-corrected bootstrap for the direct and indirect associations in these models were consistent with the conclusion that the direct and indirect associations are significantly different from zero (SE and two-sided $95 \%$ confidence interval $[\mathrm{CI}]$ values based on the bias-corrected bootstrap are reported in parentheses). These results suggest that this procedure led to a stable estimate of the distributions. All analyses were performed using AMOS (Version 18.0.0; Arbuckle, 2009) and the maximumlikelihood method.

As noted earlier, we also investigated whether humor styles moderated the relationship between the personality vulnerability factors of self-criticism and neediness and depressive symptoms using hierarchical multiple regressions with interactions represented by prod- uct terms (Aiken and West, 1991) and ensured all of the conditions for omnibus regression analysis, substantially reducing the likelihood of type I errors.

\section{RESULTS}

\section{Confirmatory Factor Analysis - Scale Structure}

Our results indicated that the model with two latent factors (benign humor and injurious humor) had an acceptable fit $\left(\chi^{2}[1]=\right.$ $0.58 ; p>0.45 ; \chi^{2} / d f=0.58$; NNFI, 0.99; CFI, 1.00; RMSEA, 0.000; $90 \% \mathrm{CI}, 0.000$ to 0.05 ). All of the factor indicators and path-loadings were substantial and statistically significant in the expected directions. To exclude other models, we also examined whether we could rule out the possibility of subsuming benign humor and injurious humor into one large humor styles construct. This single latent construct model did not fit the data: $\left(\chi^{2}[2]=21.2 ; p>0.14 ; \chi^{2} / d f=10.55\right.$; NNFI, 0.76; CFI, 0.77; RMSEA, 0.17 ; $90 \%$ CI, 0.10 to 0.24 ) and had a significantly worse fit than did the model with two latent constructs $\left(\Delta \chi^{2}[1]=20.62, p<0.001\right)$. Therefore, we used the two-latent factors model, each with two indicators, as previously demonstrated in samples of community adults using CFA by Besser A, Luyten P,

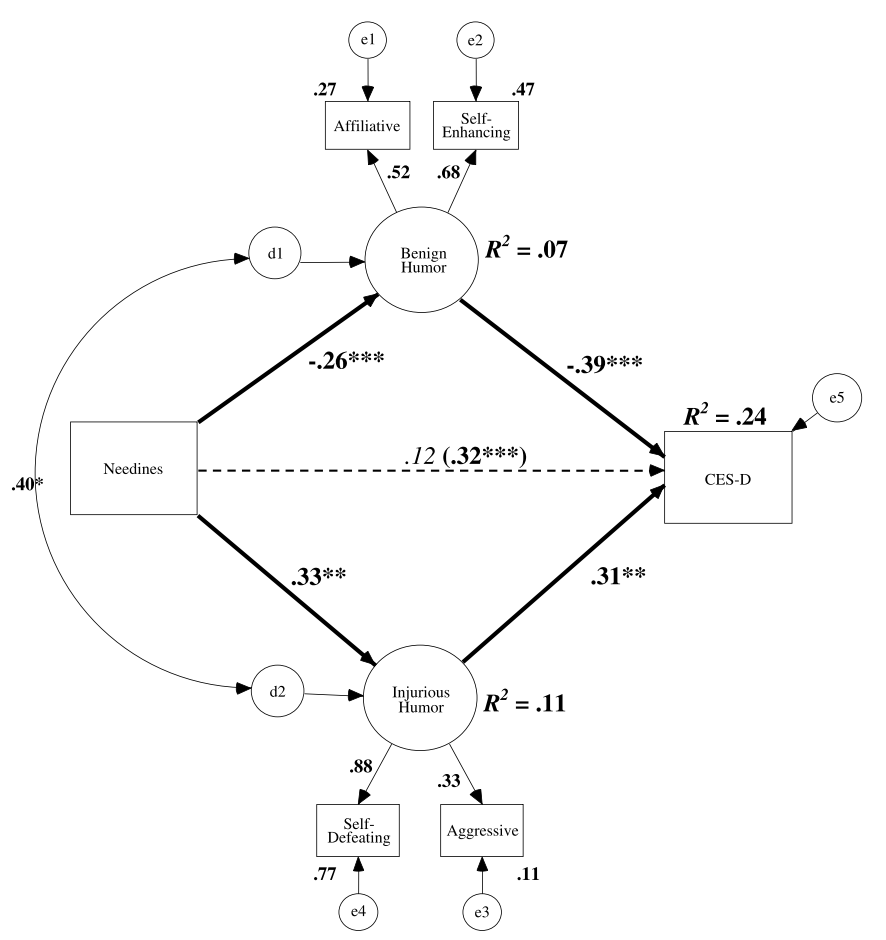

FIGURE 2. A mediational model of the relationships among neediness, humor styles, and depressive symptoms. Rectangles indicate measured variables, and the large circles represent latent constructs. Small circles reflect residuals (e). Bold numbers above or near endogenous variables represent the amount of variance explained $\left(R^{2}\right)$. The bidirectional arrow depicts covariance and unidirectional arrows depict hypothesized directional links. Standardized maximum-likelihood parameters were used. The number in parentheses is the beta value before humor-construct scores (assumed mediators) were entered into the model $\left(\Delta R^{2}=14 \%\right)$. Bold estimates are statistically significant. CES-D indicates Center for Epidemiological Studies Depression Scale. $* p<0.01$, two-tailed. $* * * p<0.001$, two-tailed. 


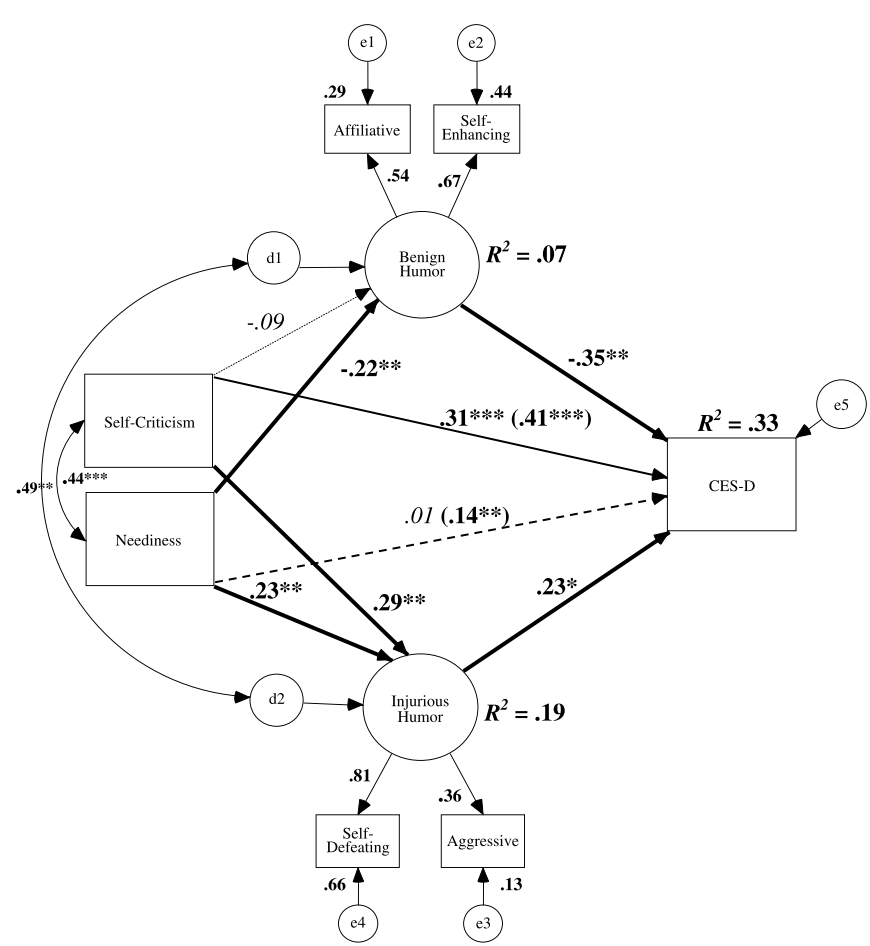

FIGURE 3. A combined mediational model of the relationships among the examined personality vulnerability factors, humor styles, and depressive symptoms. Rectangles indicate measured variables, and the large circles represent latent constructs. Small circles reflect residuals (e). Bold numbers above or near endogenous variables represent the amount of variance explained $\left(R^{2}\right)$. Bidirectional arrows depict covariance and unidirectional arrows depict hypothesized directional links. Standardized maximum-likelihood parameters were used. The numbers in parentheses are the beta values before the humor-construct scores (assumed mediators) were entered into the model $\left(\Delta R^{2}=9 \%\right)$. Bold estimates are statistically significant. CES-D indicates Center for Epidemiological Studies Depression Scale. $* p<0.05$, two-tailed. $* * p<0.01$, two-tailed. $* * * p<0.001$, two-tailed.
Mayes LC Adult attachment and distress: The mediating role of humor styles (submitted for publication, 2011), as well as in samples of university students (Besser and Zeigler-Hill, 2011; Zeigler-Hill and Besser, 2011).

\section{Direct Association Models}

Direct Association Models for Self-Criticism and Neediness

As expected (Table 1), both self-criticism and neediness were significantly associated with depressive symptoms, with self-criticism explaining $22 \%$ of the variance in depressive symptoms $(\beta=0.47, t=$ $9.80, p<0.0001$; SE, $0.52 ; 95 \%$ CI, 4.11 to $6.15 ; p<0.0001)$ and with neediness explaining $10 \%$ of the variance in depressive symptoms $(\beta=0.32, t=6.15, p<0.0001$; SE, $0.68 ; 95 \%$ CI, 2.52 to 5.20 ; $p<0.0001)$.

\section{The Combined Direct Association Model}

We also ran a SEM model that included both self-criticism and neediness simultaneously. The results for that model were similar to those of the two direct association SEM models in which self-criticism and neediness were evaluated separately. When we controlled for the shared variance between self-criticism and neediness $(r=0.44)$, both dimensions were still significantly associated with depressive symptoms $(\beta=0.41, t=7.76, p<0.0001$; SE, $0.54 ; 95 \% \mathrm{CI}, 3.40$ to 5.55 , $p<0.0001$ and $\beta=0.14, t=2.59, p<0.01 ; \mathrm{SE}, 0.65 ; 95 \% \mathrm{CI}, 0.40$ to $2.93 ; p<0.01$, respectively), explaining $24 \%$ of the variance in depressive symptoms.

\section{Mediation Models}

\section{The Mediating Model for Self-Criticism}

This model (Fig. 1) fit the observed data very well: $\chi^{2}(5)=$ $8.25 ; p>0.14 ; \chi^{2} / d f=1.65$; NNFI, 0.97; CFI, 0.99; RMSEA, 0.04; $90 \% \mathrm{CI}, 0.000$ to 0.05 . As shown in Figure 1, self-criticism was significantly associated with the use of injurious humor $(\beta=0.41$, $t=3.59, p<0.0001$; SE, $0.38 ; 95 \%$ CI, 0.61 to $2.12 ; p<0.0001)$ and this, in turn, was associated with depressive symptoms $(\beta=0.27$; $t=2.32, p<0.02$; SE, $0.47 ; 95 \%$ CI, 0.32 to $2.12 ; p<0.003)$. Selfcriticism was also significantly negatively associated with the use of benign humor ( $\beta=-0.21, t=-2.37, p<0.02$; SE, 0.43 ; $95 \% \mathrm{CI}$, -1.73 to $-0.08 ; p<0.03$ ), which, in turn, was negatively associated with depressive symptoms $(\beta=-0.38, t=-3.20, p<0.001$; SE,

\begin{tabular}{|c|c|c|c|c|c|c|c|c|c|}
\hline Variables & 1 & 2 & 3 & 4 & 5 & 6 & 7 & Mean & SD \\
\hline \multicolumn{10}{|c|}{ Personality vulnerabilities } \\
\hline 2. Neediness & $0.44 * * *$ & $\longrightarrow$ & & & & & & -0.51 & 0.81 \\
\hline \multicolumn{10}{|l|}{ Humor styles } \\
\hline 3. Affiliative & $-0.19 * * *$ & $-0.13 *$ & - & & & & & 43.62 & 6.45 \\
\hline 6. Self-defeating & $0.31 * * *$ & $0.30 * * *$ & 0.10 & $0.18 * * *$ & $0.29 * * *$ & - & & 23.09 & 8.22 \\
\hline \multicolumn{10}{|l|}{ Depressive symptoms } \\
\hline 7. CES-D & $0.47 * * *$ & $0.32 * * *$ & $-0.21 * * *$ & $-0.21 * * *$ & 0.03 & $0.21 * * *$ & $\overline{ }$ & 16.21 & 9.79 \\
\hline $\begin{array}{l}N=335 \\
* p<0.05 \text {, two-tailed. } \\
* * p<0.01 \text {, two-tailed } \\
* * * p<0.001 \text {, two-tai } \\
\text { CES-D indicates Cent }\end{array}$ & iological & epression & & & & & & & \\
\hline
\end{tabular}


$0.40 ; 95 \% \mathrm{CI},-1.92$ to $-0.43 ; p<0.001)$. Moreover, the relationship between self-criticism and depressive symptoms was mediated by high levels of injurious humor and low levels of benign humor (SE, $1.14 ; 95 \% \mathrm{CI}, 0.82$ to $5.53 ; p<0.001$ ), as indicated by the finding that, after the introduction of the humor styles as mediators, the direct path from self-criticism to depressive symptoms significantly decreased in comparison with the direct-effects model $(\beta=0.28, t=$ $3.23, p<0.001$; SE, 1.26 ; $95 \% \mathrm{CI},-0.29$ to $4.69 ; p>0.07)$.

\section{The Mediating Model for Neediness}

This model (Fig. 2) also fit the data very well: $\chi^{2}(5)=4.12 ; p>$ 0.53; $\chi^{2} / d f=0.82$; NNFI, 0.98; CFI, 1.0; RMSEA, 0.000; 90\% CI, 0.000 to 0.06 . As shown in Figure 2, neediness was significantly associated with the use of injurious humor $(\beta=0.33, t=2.71, p<$ 0.007 ; SE, $0.37 ; 95 \%$ CI, 0.31 to $1.78 ; p<0.0001)$, which, in turn, was positively associated with depressive symptoms $(\beta=0.31, t=3.00$, $p<0.003$; SE, $0.44 ; 95 \%$ CI, 0.62 to $2.29 ; p<0.0001)$. Neediness was also significantly negatively associated with the use of benign humor $(\beta=-0.26, t=-3.19, p<0.001$; SE, $0.34,95 \% \mathrm{CI},-1.82,-0.45$; $p<0.001)$, which, in turn, was negatively associated with depressive symptoms $(\beta=-0.39, t=-3.52, p<0.0001$; SE, $0.38 ; 95 \% \mathrm{CI}$, -2.01 to $-0.56 ; p<0.001)$. Importantly, as shown in Figure 2, the association between neediness and depressive symptoms was fully mediated by high levels of injurious humor and low levels of benign humor (SE, 1.12; 95\% CI, 1.01 to 5.32; $p<0.0001$ ), as indicated by the finding that, after the introduction of the humor styles as mediators, the direct path from neediness to depressive symptoms decreased and was no longer significant $(\beta=0.12 ; t=1.33$, not significant; SE, $1.30 ; 95 \% \mathrm{CI},-1.42$ to 3.46 ; not significant).

\section{The Combined Mediation Model}

We also ran an SEM model that included self-criticism and neediness, benign and injurious humor, and depressive symptoms, simultaneously. This combined mediation model (Fig. 3) fit the observed data very well: $\chi^{2}(7)=12.05 ; p>0.10 ; \chi^{2} / d f=1.72$; NNFI, 0.97; CFI, 0.99; RMSEA, $0.04 ; 90 \%$ CI, 0.000 to 0.06 . The results for this model were almost the same as those of the two mediating SEM models, which included self-criticism and neediness separately (Fig. 3). As shown in Figure 3, when we controlled for self-criticism, the association between neediness and depressive symptoms was fully mediated by high levels of injurious humor and low levels of benign humor (SE, 0.88; 95\% CI, 0.64 to $4.34 ; p<0.001$ ), whereas the association between self-criticism and depressive symptoms was largely mediated by high levels of injurious humor (SE, $0.91 ; 95 \% \mathrm{CI}$, 0.13 to $3.48 ; p<0.01)$. However, in contrast with the findings presented in Figure 1, when we controlled for neediness, we found that the association between self-criticism and depressive symptoms was not mediated by low levels of benign humor.

\section{Moderation Models}

Finally, we also performed a series of regression analyses to investigate possible moderation models - that is, whether high levels of benign and/or low levels of injurious humor interacted with selfcriticism and neediness in the prediction of depressive symptoms to moderate these relationships and whether personality interacted with depression to predict the use of injurious and benign humor. However, in these analyses, none of the interaction terms were significant.

\section{DISCUSSION}

The main finding of this study is that both self-criticism and neediness are associated with injurious humor styles, which, in turn, are associated with increased levels of depressive symptoms. This finding adds to the growing body of evidence that self-criticism and neediness are associated with maladaptive affect-regulation strategies, particularly in close interpersonal relationships, which may lead to vicious interpersonal cycles that further increase vulnerability to depression (Blatt and Luyten, 2009; Luyten et al., 2005; Wachtel, 1997). More specifically, the results of this study suggest that the use of injurious humor is one route by which individuals with high levels of self-criticism and neediness may contribute to their own stressful interpersonal environments. Although the use of such humor styles may reflect attempts to relate to others and/or attempts to regulate stress (Besser A, Luyten P, Mayes LC Adult attachment and distress: The mediating role of humor styles [submitted for publication, 2011]), these attempts are likely to fail and are associated with increased levels of depressive symptoms.

Moreover, self-criticism and particularly neediness were negatively related to the use of benign humor styles. This may indicate that individuals exhibiting high levels of self-criticism and neediness, in addition to using injurious humor in interpersonal relationships, also lack an important adaptive affect-regulation strategy (Martin, 2007; Miczo et al., 2009; Taber et al., 2007). Hence, these findings shed further light on the vulnerabilities to depression associated with these personality dimensions. More specifically, even more than high levels of self-criticism, high levels of neediness were associated with a lack of benign humor (that is, the absence of an important affectregulation strategy), leaving highly needy individuals vulnerable to symptoms of depression and feelings of despair.

The finding that adaptive humor styles do not moderate the associations between the personality vulnerability factors of selfcriticism and neediness on the one hand and depressive symptoms on the other further suggests that, even when individuals with high levels of self-criticism and maladaptive dependency use more adaptive humor styles, decreased levels of distress will not be observed. However, congruent with recent theoretical speculations (e.g., Gervais and Wilson, 2005) and empirical findings (e.g., Besser and ZeiglerHill, 2011; Besser A, Luyten P, Mayes LC Adult attachment and distress: The mediating role of humor styles [submitted for publication, 2011]; Martin, 2007; Miczo et al., 2009; Taber et al., 2007; Zeigler-Hill and Besser, 2011), the use of adaptive humor styles was associated with reduced levels of depressive symptoms.

From a clinical perspective, clinicians may want to encourage the use and appreciation of more benign humor styles, particularly in individuals with high levels of neediness. This may lead to better affect regulation and improved mood, reduce distress, and foster socalled broaden and build cycles (Fredrickson, 2001). For instance, therapists may model and encourage such humor styles by usingwhen appropriate-more affiliative humor, thus modeling the use of humor to effectively coregulate distress (Lemma, 2000). Although studies that have examined the use of humor in psychotherapy have documented a positive effect on treatment outcome and satisfaction for both clinicians and patients (Kidd et al., 2009; Ventis et al., 2001), further research is needed to investigate the potential role of humor in the treatment of highly self-critical and needy patients.

The limitations of this study include its cross-sectional design, which limits our ability to draw conclusions about causality. Further research is needed to develop a clearer understanding of the causal mechanisms and relationships among depressive symptoms, humor, and personality. It is highly likely not only that personality dimensions such as self-criticism and neediness predispose individuals to use more adaptive versus maladaptive styles of humor, but also that depressive symptoms are likely to inhibit the ability to use and appreciate humor, leading to a vicious cycle characterized by increasing levels of depressive symptoms.

An additional limitation concerns the generalizability of the present results beyond Israeli community adults. This concern stems from the fact that Israelis are relatively collectivistic (Oyserman et al., 
2002), which may affect the relationships among the study variables. This limitation suggests that future research should attempt to replicate the present findings in a culture that is less collectivistic, as well as in different contexts, such as among individuals dealing with natural disasters, migration, poverty, and others. Moreover, this study was conducted in a nonclinical community sample; therefore, the results may not generalize to other samples. Future research should examine the effects of humor in clinical samples, particularly its effects on treatment outcomes.

The fact that we investigated only one potential mediator (i.e., humor styles) presents an additional limitation. Future research projects should investigate multiple mediating mechanisms simultaneously. Finally, this study also relied exclusively on self-report measures and further observational and experimental research in this area is, therefore, clearly needed.

Despite these limitations, our findings not only suggest that high levels of self-criticism and neediness are related to failed attempts to relate to others and to the interpersonal regulation of affect through the use of injurious humor styles but also that individuals with high levels of self-criticism and neediness may lack an important affect-regulation strategy (i.e., benign humor). These findings may have important consequences for theories about mood and resilience and for the role of humor in psychotherapy and clinical interventions more generally. Further research in clinical samples and the translation of these findings into intervention strategies are needed.

\section{ACKNOWLEDGMENTS}

The authors thank the research assistants of Sapir Academic College, Israel, and Ben-Gurion University of the Negev, Eilat Campus, Israel, for their valuable assistance in data collection. They also thank all those who participated in this study. Finally, they thank the anonymous reviewers for their constructive suggestions and comments on an earlier draft of the paper.

\section{DISCLOSURE}

The authors have no conflicts of interest to declare.

\section{REFERENCES}

Aiken LS, West SG (1991) Multiple regression: Testing and interpreting interactions. Newbury Park, CA: Sage.

Anderson JC, Gerbing DW (1988) Structural equation modeling in practice: A review and recommended two-step approach. Psychol Bull. 103:411-423.

Arbuckle JL (2009) Amos 18 user's guide. Crawfordville, FL: Amos Development Corporation.

Baron RM, Kenny DA (1986) The moderator-mediator variable distinction in social psychological research: Conceptual, strategic, and statistical considerations. $J$ Pers Soc Psychol. 51:1173-1182.

Beck AT (1983) Cognitive therapy of depression: New perspectives. In Clayton IJ, Barrett JE (Eds), Treatment of depression: Old controversies and new approaches (pp 265-290). New York: Raven.

Besser A (2004) Self- and best-friend assessments of personality vulnerability and defenses in the prediction of depression. Soc Behav Pers. 32:559-594.

Besser A, Guez J, Priel B (2008a) The associations between self-criticism and dependency and incidental learning of interpersonal and achievement words. Pers Individ Differ. 44:1696-1710.

Besser A, Priel B (2005) The apple does not fall far from the tree: Attachment styles and personality vulnerabilities to depression in three generations of women. Pers Soc Psychol Bull. 31:1052-1073.

Besser A, Priel B (2008) Attachment, depression, and fear of death in older adults: The roles of neediness and perceived availability of social support. Pers Individ Differ. 44:1711-1725.

Besser A, Priel B (2010) Personality vulnerability, low social support, and maladaptive cognitive emotion regulation under ongoing exposure to terrorist attacks. J Soc Clin Psychol. 29:166-201.
Besser A, Priel B (2003) Trait vulnerability and coping strategies in the transition to motherhood. Curr Psychol. 22:57-72.

Besser A, Priel B (2011) Dependency, self-criticism and negative affective responses following imaginary rejection and failure threats: meaning-making processes as moderators or mediators. Psychiatry. 2011 Spring;74(1):31-40.

Besser A, Vliegen N, Luyten P, Blatt SJ (2008b) Vulnerability to postpartum depression from a psychodynamic perspective: Systematic empirical base commentary on issues raised by Blum (2007). Psychoanal Psychol. 25: $392-410$.

Besser A, Zeigler-Hill V (2011) Pathological forms of narcissism and perceived stress during the transition to the university: The mediating role of humor styles. Int J Stress Manag. 18:197-221. DOI: 10.1037/a0024826.

Blatt SJ (1974) Levels of object representation in anaclitic and introjective depression. Psychoanal Study Child. 24:107-157.

Blatt SJ (1991) A cognitive morphology of psychopathology. J Nerv Ment Dis. 179:449-458.

Blatt SJ (2004) Experiences of depression: Theoretical, clinical, and research perspectives. Washington, DC: American Psychological Association.

Blatt SJ (2008) Polarities of experience: Relatedness and self-definition in personality development, psychopathology, and the therapeutic process. Washington, DC: American Psychological Association.

Blatt SJ, D'Afflitti JP, Quinlan DM (1976) Experiences of depression in normal young adults. J Abnorm Psychol. 85:383-389.

Blatt SJ, Luyten P (2009) A structural-developmental psychodynamic approach to psychopathology: Two polarities of experience across the life span. Dev Psychopathol. 21:793-814.

Blatt SJ, Luyten P (2010) Reactivating the psychodynamic approach to classify psychopathology. In Millon T, Krueger RF, Simonsen E (Eds), Contemporary directions in psychopathology. Scientific foundations of the DSM-Vand ICD-11 (pp 483-514). New York: Guilford Press.

Blatt SJ, Quinlan DM, Chevron ES, McDonald C, Zuroff DC (1982) Dependency and self-criticism: Psychological dimensions of depression. J Consult Clin Psychol. 50:113-124.

Blatt SJ, Zohar AH, Quinlan DM, Luthar S, Hart B (1996) Levels of relatedness within the dependency factor of the Depression Experiences Questionnaire for Adolescents. J Pers Assess. 67:52-71.

Blatt SJ, Zohar AH, Quinlan DM, Zuroff DC, Mongrain M (1995) Subscales within the Dependency factor of the Depressive Experiences Questionnaire. J Pers Assess. 64:319-339.

Butzer B, Kuiper NA (2008) Humor use in romantic relationships: The effects of relationship satisfaction and pleasant versus conflict situations. J Psychol. $142: 245-260$.

Cann A, Norman MA, Welbourne JL, Calhoun LG (2008) Attachment styles, conflict styles, and humour styles: Inter-relationships and associations with relationship satisfaction. Eur J Pers. 22:131-146.

Campos CR, Besser A, Blatt SJ (2010) The mediating role of self-criticism and dependency in the association between perceptions of maternal caring and depressive symptoms. Depress Anxiety. 27:1149-1157.

Campos CR, Besser A, Blatt SJ (2011) The relationships between defenses and experiences of depression: An exploratory study. Psychoanal Psychol. 28:196-208

Eaton WW, Muntaner C, Smith C, Tien A, Ybarra M (2004) Center for Epidemiologic Studies Depression Scale: Review and revision (CESD and CESDR). In Maruish ME (Ed), The use of psychological testing for treatment planning and outcome assessment (3rd ed). Mahwah, NJ: Erlbaum.

Fitts SD, Sebby RA, Zlokovich M (2009) Humor styles as mediators of the shynessloneliness relationship. North Am J Psychol. 11:257-272.

Fonagy P, Steele M, Steele H, Higgitt A, Target M (1994) The Emmanuel Miller Memorial Lecture 1992. The theory and practice of resilience. J Child Psychol Psychiatry. 35:231-257.

Fredrickson BL (2001) The role of positive emotions in positive psychology. The broaden-and-build theory of positive emotions. Am Psychol. 56:218-226.

Frewen P, Brinker J, Martin R, Dozois DJA (2008) Humor styles and personalityvulnerability to depression. Humor. 21:179-195.

Gervais M, Wilson DS (2005) The evolution and function of laughter and humor: A synthetic approach. $Q$ Rev Biol. 80:395-430.

Hoyle RH, Smith GT (1994) Formulating clinical research hypotheses as structural equation models: A conceptual overview. J Consult Clin Psychol. 62:429-440

$\mathrm{Hu}$ LT, Bentler PM (1999) Cutoff criteria for fit indexes in covariance structure analysis: Conventional criteria versus new alternatives. Struct Eq Model. 6:1-55. 
Kazarian SS, Martin RA (2004) Humor styles, personality, and well-being among Lebanese university students. Eur J Pers. 18:209-219.

Kelloway EK (1998) Using Lisrel for structural equation modeling: A researcher's guide. Newbury Park, CA: Sage.

Kidd SA, Miller R, Boyd GM, Cardeña I (2009) Relationships between humor, subversion, and genuine connection among persons with severe mental illness. Qual Health Res. 19:1421-1430

Kuiper NA, Leite C (2010) Personality impressions associated with four distinct humor styles. Scand J Psychol. 51:115-122.

Lemma A (2000) Humour on the couch: Exploring humour in psychotherapy and everyday life. London: Whurr Pub Ltd.

Lilliefors H (1967) On the Kolmogorov-Smirnov test for normality with mean and variance unknown. J Am Stat Assoc. 62:399-402.

Luyten P, Corveleyn J, Blatt SJ (2005) The convergence among psychodynamic and cognitive-behavioral theories of depression: A critical overview of empirical research. In Corveleyn J, Luyten P, Blatt SJ (Eds), The theory and treatment of depression: Towards a dynamic interactionism model (pp 107-147). Mahwah, NJ: Erlbaum.

Luyten P, Fonagy P, Lemma A, Target M (2011) Mentalizing and depression. In Bateman A, Fonagy P (Eds), Handbook of mentalizing in mental health practice. Washington, DC: American Psychiatric Association.

Mallinckrodt B, Abraham TW, Wei M, Russell DW (2006) Advances in testing statistical significance of mediation effects. J Counsel Psychol. 53:372-378.

Martin RA (2001) Humor, laughter, and physical health: Methodological issues and research findings. Psychol Bull. 127:504-519.

Martin RA (2007) The psychology of humor: An integrative approach. New York, NY: Academic Press.

Martin RA, Puhlik-Doris P, Larsen G, Gray J, Weir K (2003) Individual differences in uses of humor and their relation to psychological well-being: Development of the Humor Styles Questionnaire. J Res Pers. 37:48-75.

Miczo N, Averbeck JM, Mariani T (2009) Affiliative and aggressive humor, attachment dimensions, and interaction goals. Commun Stud. 60:443-459.

Mongrain M (1998) Parental representations and support-seeking behaviors related to Dependency and Self-Criticism. J Pers. 66:151-173.

Mongrain M, Leather F (2006) Self-criticism and dependence predict the recurrence of major depression. J Clin Psychol. 62:705-713.

Mongrain M, Lubbers R, Struthers W (2004) The power of love: Mediation of rejection in roommate relationships of dependents and self-critics. Pers Soc Psychol Bull. 30:94-105.

Oyserman D, Coon HM, Kemmelmeier M (2002) Rethinking individualism and collectivism: Evaluation of theoretical assumptions and meta-analyses. Psychol Bull. 128:3-72.

Priel B, Besser A (1999) Vulnerability to postpartum depressive symptomatology:
Dependency, self-criticism, and the moderating role of antenatal attachment. J Soc Clin Psychol. 18:240-253.

Priel B, Besser A (2000) Dependency and self-criticism among first-time mothers: The roles of global and specific support. J Soc Clin Psychol. 19:437-450.

Radloff RS (1977) The CES-D Scale: A self-report depression scale for research in the general population. Appl Psychol Meas. 1:385-401.

Rude SS, Burnham BL (1995) Connectedness and neediness: Factors of the DEQ and SAS dependency scales. Cogn Ther Res. 19:323-340.

Saroglou V, Scariot C (2002) Humor styles questionnaire: Personality and educational correlates in Belgian high school and college students. Eur J Pers. 16:43-54.

Schulte FS, Mongrain M, Flora DB (2008) Healthy and unhealthy dependence: Implications for major depression. Br J Clin Psychol. 47:341-353.

Shapiro SS, Wilk MB (1965) An analysis of variance test for normality. Biometrika. 52:591-611.

Shrout PE, Bolger N (2002) Mediation in experimental and nonexperimental studies: New procedures and recommendations. Psychol Meth. 7:422-445.

Smirnov NV (1948) Tables for estimating the goodness of fit of empirical distributions. Ann Math Stat. 19:279.

Taber KH, Redden M, Hurley RA (2007) Functional anatomy of humor: Positive affect and chronic mental illness. J Neuropsychiatry Clin Neurosci. 19: $358-362$.

Thompson R, Zuroff DC (1998) Dependent and self-critical mothers' responses to adolescent autonomy and competence. Pers Individ Differ. 24:311-324.

Thompson R, Zuroff DC (1999) Development of self-criticism in adolescent girls: Roles of maternal dissatisfaction, maternal coldness, and insecure attachment. $J$ Youth Adolesc. 28:197-210.

Vaillant GE (2000) Adaptive mental mechanisms: Their role in positive psychology. Am Psychol. 55:89-98.

Vaillant GE (1977) Adaptation to life. Toronto: Little, Brown, \& Co.

Ventis WL, Higbee G, Murdock SA (2001) Using humor in systematic desensitization to reduce fear. J Gen Psychol. 128:241.

Wachtel PL (1997) Psychoanalysis, behavior therapy, and the relational world. Washington, DC: American Psychological Association Press.

Whiffen VE, Aube J, Thompson JM, Campbell TL (2000) Attachment beliefs and interpersonal contexts associated with dependency and self-criticism. J Soc Clin Psychol. 19:184-205.

Zeigler-Hill V, Besser A (2011) Humor style mediates the association between pathological narcissism and self-esteem. Pers Individ Differ. 50:1196-1201.

Zuroff DC, Mongrain M, Santor DA (2004) Conceptualizing and measuring personality vulnerability to depression: Comment on Coyne and Whiffen (1995). Psychol Bull. 130:489-511. 